\title{
(Des)Construindo o sujeito neoliberal a partir de Foucault
}

\section{(De)Constructing the neoliberal subject with Foucault}

\author{
*Marta Nunes da Costa
}

\begin{abstract}
Resumo: O que é o sujeito neoliberal? Quem é ele? Como se torna o que é ou aparenta ser? O que significaria a transformação deste sujeito em outro? O objetivo deste artigo é tentar responder a estas questões, tendo Foucault como principal interlocutor. Para isso, este artigo tem três momentos. No primeiro momento, reconstruo o horizonte conceitual foucaultiano onde a questão da subjetividade se coloca. No segundo momento, procuro identificar elementos que nos permitem caracterizar o sujeito neoliberal de hoje; um sujeito que assimila e incorpora na sua própria construção os valores e ideologias do mercado. Por fim, identifico os elementos foucaultianos que devem ser mantidos para transformar o sujeito atual num seu 'outro', imaginando que tipo de nova subjetividade podemos construir hoje.
\end{abstract}

Palavras-chave: Foucault, liberdade, neoliberalismo, resistência, subjetividade.

\begin{abstract}
What is the neoliberal subject? Who is $\mathrm{s} / \mathrm{he}$ ? How does $\mathrm{s} /$ he become what it is or appears to be? What could it be the transformation of this subject into another? The goal of this article is to answer these questions having Foucault as principal interlocutor. This article has three sections. In the first section, I reconstruct the Foucauldian conceptual horizon in order to characterize the conditions where subjectivity becomes a question. In the second section, I aim at identifying the elements that allows us to characterize today's neoliberal subject: a subject that assimilates and incorporates in his own construction the values and ideologies of the market. Finally, I identify the Foucauldian elements that should be kept in order to transform the neoliberal subject into an-Other, trying to imagine what kind of subjectivity can one build today.
\end{abstract}

Keywords: Foucault, freedom, neoliberalism, resistance, subjectivity.

* Doutorada em Ciência Política pela New School for Social Research, NY, Professora Adjunta de Filosofia da UFMS. <nunesdacosta77@gmail.com> 


\section{Reconstruindo o horizonte conceitual foucaultiano - a questão da subjetividade}

A propósito dos seus estudos sobre o poder, Foucault enfatizava o si, mas antes 'a maneira pela qual um ser se transforma em sujeito'. ${ }^{1}$ Partindo de um horizonte Kantiano de comprometimento com o projeto de Aufklärung, que, poderíamos dizer, coincide com o projeto de emancipação humana, Foucault questiona as relações entre racionalização e poder. Um questionamento que ecoa, mas se diferencia, daquele feito pela Escola de Frankfurt de Adorno e Horkheimer. Mas o que significa isto? O que significa este questionamento das relações entre racionalização e poder? $\mathrm{E}$ por que isso é condição necessária para se compreender ou vislumbrar um sentido ao processo de constituição da subjetividade?

Falar de racionalização aponta para um desdobramento da Razão. A Razão, com maiúscula, faculdade distintiva dos seres humanos, capaz de conduzir o ser humano - enquanto indivíduo e enquanto espécie - de um ponto de imaturidade a um ponto de crítica, reflexão e emancipação, isto é, de liberdade, não é apenas isto. A Razão é produto de uma escolha, reflexo de uma história que consolida uma narrativa. A escolha é a escolha daquilo que passará a estar visível e do que passará a ser valorizado. O visível só se constrói a partir do invisível; porém, quer um, quer outro existem de forma igual; um alimenta-se do outro, dependem um do outro. Se a Razão é o visível, o que seria o não visível? A não-Razão? A história da filosofia parece sugerir que sim, que o não-Razão não deve ser entendida tanto como negação de Razão, mas o 'Outro' da Razão. O que seria o 'Outro'? Emoção, paixão, e tantos outros. Mas daí não se segue que o 'Outro' da Razão seja irracional. Aqui é preciso introduzir a distinção entre Razão de racionalidade. Esta escolha, que parecia a afirmação de uma Razão Universal, ao manifestar-se como escolha concreta particularizou-se, isto é, ela exigiu a sua instanciação de forma mais explicita, evidente, e o fez através da progressiva associação entre Razão (entendida como faculdade (e) ideal) e racionalidade. A racionalidade por sua vez estreita-se numa racionalidade também ela específica - uma racionalidade instrumental, uma racionalidade que se desenvolve refletindo a estrutura social, económica e política e incorporando as finalidades de um modo de produção capitalista que se consolida de forma hegemónica. A nova economia política, disciplina que já Hegel reconhecera como especificamente moderna, do Estado moderno, impõe o estreitamento

1 Ver Foucault, M., "Le sujet et le pouvoir" em Dits et écrits, tome IV, texte n. 306. Também em Rabinow, Michel Foucault: Beyond Structuralism and Hermeneutics, Chicago, The University of Chicago Press, 1982, p. 208-226 
da Razão como racionalidade instrumental. Foi esta racionalidade que Horkheimer e Adorno denunciaram e criticaram de forma feroz na Dialética do Esclarecimento, mostrando que a promessa de progresso traz consigo tendências regressivas.

Foucault, embora de outra linhagem filosófica, partilha as preocupações da teoria crítica e, como defendi num outro trabalho ${ }^{2}$, é um autor que toma a crítica como ponto de partida conceitual e metodológico. Nos seus textos sobre governamentalidade, Foucault anuncia como a proposta neoliberal se traduz necessariamente num projeto de transformação da subjetividade. Para compreender a dimensão e radicalidade desta categoria, é preciso esclarecer primeiro a relação entre subjetividade, poder, conhecimento e verdade.

No texto "O sujeito e o poder", acima mencionado, Foucault rejeita a leitura essencialista de 'poder' e propõe uma perspectiva ou investigação crítica sobre a questão. 'Poder' não é uma coisa determinada, ossificada, objetivada, mas antes um conjunto de relações que são necessariamente modos de ação de alguns sobre outros (FOUCAULT, 1995, p. 242). O poder é sempre ato, ação, de um sobre outro. Toda a ação é atualização de possibilidade entre muitas outras possibilidades, suportada por estruturas permanentes. Por isso, o poder é "ação sobre a ação, sobre ações eventuais, ou atuais, futuras ou presentes" (FOUCAULT, 1995, p. 243). O poder orienta, sugere, ativa condutas, isto é, ele gera uma ordenação de condutas de acordo com uma direção especifica. Neste contexto o autor diz

O exercício do poder consiste em "conduzir condutas" e em ordenar a probabilidade. O poder, no fundo, é menos da ordem do afrontamento entre dois adversários, ou do vínculo de um com relação ao outro, do que da ordem do "governo". Devemos deixar para este termo a significação bastante ampla que tinha no século XVI. Ele não se referia apenas às estruturas políticas e à gestão dos Estados; mas designava a maneira de dirigir a conduta dos indivíduos ou dos grupos: governo das crianças, das almas, das comunidades, das famílias, dos doentes. Ele não recobria apenas formas instituídas e legitimas de sujeição política ou económica; mas modos de ação mais ou menos refletidos e calculados, porem todos destinados a agir sobre as possibilidades de ação dos outros indivíduos. Governar, neste sentido, é estruturar o eventual campo de ação dos outros (FOUCAULT, 1995, p. 244, meu itálico).

O poder requer a liberdade como seu horizonte mais amplo, isto é, "não há relação de poder onde as determinações estão saturadas [...] mas apenas quando ele pode se deslocar e, no limite, escapar" (idem). A liberdade é a condição necessária de existência do poder que é sempre

2 COSTA, M. N. Redefining Individuality. Vila Nova Famalicão: Húmus Ed., 2011 
um exercício de determinação e objetivação de condutas. Por isso Foucault introduz o conceito de 'agonismo', isto é, "[...] de uma relação que é, ao mesmo tempo, de incitação recíproca e de luta; trata-se portanto, menos de uma oposição de termos que se bloqueiam mutuamente do que de uma provocação permanente" (FOUCAULT, 1995, p. 245).

Aceitar que o poder, afinal, tem uma relação absolutamente necessária e interdependente com a liberdade, obriga-nos a rever uma série de relações conceituais que muitas vezes aceitamos de forma quase dogmática, por exemplo, obriga-nos a rever o próprio conceito e prática de liberdade. Olhando para a tradição da teoria política percebemos que há formas distintas de conceber a liberdade. Rousseau é um autor onde as várias leituras de liberdade acabam por convergir, explicitando aquilo que se viria a tornar um entendimento 'moderno' do conceito.

Rousseau pensa a liberdade em três sentidos analiticamente distintos, mas interdependentes. O primeiro sentido é a liberdade natural: aquela liberdade descrita no Segundo Discurso nos primeiros estágios da humanidade, a liberdade como capacidade de escolha ou capacidade de agir contra o instinto e inclinação, i.e., capacidade de resistência ao mundo da natureza. Esta é uma das características que segundo o autor distingue os seres humanos das outras espécies, e que por sua vez torna a ação moral possível. A liberdade natural implica assim o movimento de resistência do agente (que traz consigo a consciência de si mesmo e da ação executada) e antecipa a atribuição de significado à ação (significado moral, i.e., intencional que não se reduz ao determinismo natural). ${ }^{3} \mathrm{Em}$ segundo lugar encontramos uma outra concepção de liberdade, que seria a liberdade republicana entendida como não-dominação, isto é, onde a lei protege o indivíduo da sujeição à vontade de outrem, logo, avançando um argumento contra toda a dependência pessoal (argumento visível no Segundo Discurso e também evidente n' O Contrato Social). Tendo em conta que nada pode justificar um sistema de dominação e que "as palavras escravidão e direito são contraditórias'" (ROUSSEAU, 1999, p. 18), o pacto social deve ser compreendido como passo necessário para a preservação de todos mantendo a dignidade e liberdade de todos também. É neste contexto que num tom provavelmente enigmático Rousseau afirma que é possível criar uma associação legítima e manter a mesma liberdade na medida em que "cada qual, dando-se por inteiro, a condição é igual para todos, e sendo a condição igual para todos ninguém

3 No livro I, capítulo IV d'O Contrato Social Rousseau diz claramente que a liberdade é a característica do homem que o torna humano, logo, a sua alienação é impossível: "Renunciar à liberdade é renunciar à qualidade de homem, aos direitos da humanidade, até aos próprios deveres. Tal renuncia é incompatível com a natureza do homem, e subtrair toda liberdade a sua vontade é subtrair toda moralidade a suas ações." (ROUSSEAU, 1999, p. 15). 
tem interesse em torna-la onerosa para os demais." (ROUSSEAU, 1999, p. 21), ou seja, pela alienação total de cada associado seria possível criar uma união perfeita porque "cada um, dando-se a todos, não se dá a ninguém" (idem). O que isto significa? Significa a transformação da liberdade natural em liberdade civil. Este é o terceiro sentido de liberdade em Rousseau, que se torna visível e ganha corpo com a criação do 'soberano'. A liberdade civil passa a existir apenas depois da passagem do estado de natureza ao estado civil; é a liberdade que passa a orientar as ações do indivíduo de acordo com um senso de justiça e com a moral. ${ }^{4} \mathrm{~A}$ liberdade civil transforma o homem: do homem animal, guiado pelo instinto, pela preservação e pela empatia, o homem humaniza-se, passando a exercitar a razão e com ela, a sua capacidade de aperfeiçoamento. Esta liberdade corresponde ao movimento de igualização entre os sujeitos num duplo sentido: por um lado, ela torna todos iguais perante a lei civil; por outro lado, ela representa o limite entre si/indivíduo e a vontade geral. Há ainda uma quarta conceitualização de liberdade, a saber, a liberdade moral. Se a liberdade civil é a liberdade que emancipa o homem do mundo da natureza, que lhe confere e atribui uma identidade humana, singular e única porque com ela o indivíduo pode aperfeiçoar-se pela razão e inteligência, a liberdade moral é "[a] única que torna o homem verdadeiramente senhor de si [...]" (ROUSSEAU, 1999, p. 26). O que significa ser senhor de si, e porque é importante para Rousseau compreender a liberdade neste sentido pleno de autonomia? O indivíduo torna-se autónomo, senhor de si, quando determina as suas ações não por impulso, mas por "obediência à lei que se prescreveu a si mesmo" (idem). Antecipando Kant, Rousseau vai identificar liberdade moral com obediência exclusiva à lei, e esta autonomia afirma consigo a capacidade de a liberdade determinar a natureza e transformar o mundo. É neste sentido que devemos compreender a última frase do livro I: "em vez destruir a igualdade natural, o pacto fundamental substitui, ao contrário, por uma igualdade moral e legítima aquilo que a natureza poderia trazer de desigualdade física entre os homens, e, podendo ser desiguais em força ou em talento, todos se tornam iguais por convenção e de direito" (ROUSSEAU, 1999, p. 30).

Esta digressão por Rousseau foi feita com o intuito de apontar, a partir de um único autor, as diferentes conceitualizações ou perspectivas de 'liberdade'. Ora estas conceitualizações conduzem a uma relação indissociável entre a categoria de 'sujeito' ou 'subjetividade' e a categoria

4 Rousseau diz "[...] assumindo a voz do dever o lugar do impulso físico, e o direito o do apetite, o homem, que até então não levara em conta senão a si mesmo, se viu obrigado a agir com base em outros princípios e a consultar sua razão antes de ouvir seus pendores." (ROUSSEAU, 1999, 26, meu itálico) 
de 'liberdade'; por outras palavras, a liberdade manifesta-se através do sujeito que é livre. Porém, Foucault vai transformar este entendimento. Como? Criticando a forma como este mesmo conceito se construiu historicamente. A partir de um horizonte pré-determinado de pensamento e prática discursiva (mas não só) Foucault buscou, pela crítica, romper com o discurso dominante, atrevendo-se a pensar o impensável, como aliás Tocqueville também o fizera antes dele, ao visitar os Estados Unidos da América e ao escrever sobre a tese radical de 'igualdade de condições' ${ }^{5}$ Esta ruptura começa pela sugestão de que o 'sujeito' não é apenas a ousia, upokeimenon ou tode ti dos Gregos, i.e., a substância da liberdade, o suporte ou o exemplar concreto desta, mas antes, alguém/ algo que é sujeitado a uma série de práticas e processos disciplinadores que o impede de se (auto)conceber de outra forma e que o dirige para ser, ou se tornar, algo que possa ser 'governado'.

As relações de poder são as condições de possibilidade para a constituição do conhecimento e para a constituição da subjetividade, i.e., elas são o elemento a priori, pressuposto pelo próprio a priori histórico, que produz a verdade não como 'dado' mas como 'problema' - considerado formalmente, o poder não vê nem fala mas o poder é o que 'nos permite ver e falar' (COSTA, 2011, p. 151, minha tradução).

Foucault obriga-nos a confrontar o óbvio que, por ser óbvio, temos a tendência de negar, a saber, que a 'liberdade' que nos atribuímos a nós mesmos está já enquadrada num sistema pré-definido de relações que estabelecem as condições de possibilidade da nossa ação, do exercício da nossa vontade. Mas será que a liberdade pensada a partir de um horizonte de relações de poder, traduzidas na governamentalidade, implica que abdiquemos do ideal original de emancipação ou autonomia individual? Por outras palavras, se governamentalidade é, como na raiz francesa da palavra, governar (os corpos, as almas, as ações, os desejos) e mentalidade (as ideias, os conceitos, a construção do horizonte que nos permite pensar e criticar), será que tudo é pré-definido? E não seria a predefinição da ação humana o prenúncio do fim da liberdade, pelo menos pensada no sentido moderno anteriormente mencionado a propósito de Rousseau?

Claramente, o ponto de partida para Foucault é o indivíduo, ou seja, o ser humano tornado sujeito, i.e., como efeito de poder, como resultado de um processo levado a cabo pela sociedade disciplinadora que visa criar indivíduos para melhor os controlar e manipular. Como diz $\mathrm{McHoul}$ e Grace

\footnotetext{
5 Ver Tocqueville, A. Democracia na América.
} 
O poder é simultaneamente reflexivo e impessoal. Age de um modo relativamente autónomo e produz sujeitos tal como os sujeitos se reproduzem a eles mesmos. O importante é não ignorar o sujeito ou negar a sua existência [...] mas antes examinar a sujeição [assujetissement], os processos de construção dos sujeitos em e como uma coleção de técnicas ou rasgos de poder que correm pela totalidade de um corpo social particular (MCHOUL, GRACE, 1992, p. 22).

O poder normalizador, que é sobretudo o poder invisível, traduz-se na progressiva criação de indivíduos - sujeitos - mas que, no entanto, não abdicam da reivindicação de autonomia, isto é, do ideal moderno de emancipação presente nas diferentes perspectivas oferecidas por Rousseau. Temos aqui a tensão presente na totalidade do projeto Foucaultiano - ao mesmo tempo que o autor quer compreender a invenção do sujeito e do homem, em última análise ele não abdica do ideal moderno de autonomia, adoptando a crítica como seu método, ideal regulador e prática ética. O potencial emancipatório da crítica será explorado no terceiro momento deste artigo, a partir de uma análise do conceito de parresía e suas implicações na construção da subjetividade. Por agora quero olhar para a forma como o 'sujeito neoliberal' se constrói e tentar identificar os pontos distintivos entre esta constelação de subjetividade do início do século XXI com a leitura proposta por Foucault do sujeito das décadas de 1960 e 1970.

\section{Em busca do sujeito neoliberal?}

Neste momento procuro identificar elementos que nos permitem caracterizar o sujeito neoliberal de hoje. Para isso temos que compreender de que forma este sujeito se distancia do sujeito moderno, e por sujeito moderno entendo o sujeito 'criado' a partir de Rousseau, consolidado com Kant e presente até metade do século XX. Como diz McHoul e Grace,

Foucault desafia duas concepções dominantes de modernidade [...] A primeira caracteriza a nossa época moderna primeiramente pela existência de um modo de produção capitalista. A luta dominante dentro da nossa sociedade é, assim, uma luta de classes entre a burguesia e a classe trabalhadora. Isto forma a base da análise Marxista da modernidade. A segunda, associada aos escritos de Marx Weber, opõe a modernidade ao 'tradicionalismo' em termos da evolução da razão. Os conhecimentos científicos são a instanciação mais exemplar da maturidade da razão. Mas concomitantemente com este desenvolvimento vem o seu lado negativo: a racionalidade instrumental. Weber defendia que a evolução de um sistema burocrático racional, mas despersonalizado, é a característica dominante da sociedade moderna e a dos subprodutos alienantes da profusão de práticas 'esclarecedoras' (McHOUL, GRACE, 1993, p. 62). 
Percebemos por esta citação que, na altura em que Foucault escreveu, estas eram efetivamente as duas leituras dominantes da modernidade. Uma leitura feita através da lente marxista, onde as lutas de classes são protagonistas da história universal; outra leitura, de cunho Weberiano, que de uma forma quase Adorniana demonstra como o sucesso da razão é indissociável da proliferação de tendências regressivas, irracionais e alienantes. Foucault avança estas leituras e introduz um novo elemento, característico da modernidade, a saber, os novos mecanismos de poder. Estes novos mecanismos são aqueles que se prendem com a gestão, governo e administração da 'vida' no sentido de bios. Foucault diz

\begin{abstract}
Este novo mecanismo de poder é mais dependente dos corpos e do que estes fazem do que da terra e seus produtos. É um mecanismo de poder que permite que tempo e trabalho, mais do que riqueza e mercadorias, sejam extraídos dos corpos. É um tipo de poder que é constantemente exercido por meio de uma vigilância, mais do que de forma descontínua por meio de um sistema de direitos ou obrigações distribuídas ao longo do tempo. Pressupõe uma grelha cerrada de coerções materiais, mais do que a existência física de um soberano. É em última análise dependente do princípio, que introduz uma genuinamente nova economia de poder, de que um deve ser simultaneamente capaz de aumentar as forças sujeitadas e melhorar a força e a eficácia daquilo que as sujeita (FOUCAULT, 1980, p. 104, meu itálico).
\end{abstract}

Esta passagem é reveladora: Foucault diz com toda a clareza que o que é realmente específico da modernidade não são as formas coercitivas que o Estado dispõe para controlar os corpos, mas antes, os métodos que permitem extrair tempo e trabalho dos corpos, ressalvando que esta extração é feita dentro de um horizonte onde os corpos dos sujeitos não estão fisicamente limitados, nem são fisicamente forçados a fazer algo. Pelo contrário, esses corpos agora têm direitos legais que os protegem da 'exploração', e que lhes garantem igualdade (contratual) e liberdade. Foucault vira do avesso a nossa compreensão intuitiva ou naturalizada de poder, de liberdade, de direitos. O poder não é aquilo que reprime ou que exclui; o poder é sempre produtivo, ele produz sujeitos que (re)produzem a realidade, seus objetos, seus rituais, suas verdades. Os sujeitos produzem-se a si mesmos no horizonte definido pela produção e reprodução constante de sistemas de relações de poder. Esta produção e reprodução dá-se por meio de novas técnicas e disciplinas. As disciplinas visam, a partir de uma compreensão do que é 'verdadeiro' acerca de si, transformar o sujeito de forma a que ele se ajuste às necessidades de cada época. A sociedade de vigilância, que começa a ganhar corpo com 
o Panopticon de Bentham introduzido nos estabelecimentos prisionais, vem operar uma transformação na forma como o sujeito se comporta e se vê a si mesmo. O sujeito sabe que é observado, e é treinado, por esta sensação, para tornar os seus comportamentos mais dóceis, menos violentos; porém, esta observação traduz uma relação absolutamente assimétrica, em que todos são vistos, mas ninguém vê o observador. Este poder disciplinador é, para Foucault, a grande invenção da sociedade burguesa e deve ser interpretado como a condição de possibilidade para o modo de produção capitalista, contestando assim a tese Marxista de que as forças económicas determinam necessariamente as forças sociais. A disciplina introduzida e interiorizada pelos sujeitos cria o espaço ideal para a extração do tempo e trabalho e produz (transformando) sujeitos em indivíduos obedientes, a partir do domínio dos corpos. ${ }^{6}$ Com efeito, parece que "o capitalismo não teria sido possível sem a 'inserção' controlada dos corpos nos processos de produção" (McHOUL, GRACE, 1993, p. 72). A acumulação dos corpos gera condições para a acumulação do capital cada vez mais acelerada.

Esta acumulação tem vindo a acentuar-se cada vez mais, e de forma desproporcional, a partir da guinada neoliberal protagonizada por Reagan e Thatcher nos anos 1980. Esta proposta, que na década de $1960 \mathrm{mal}$ tinha apoiantes, tornou-se dominante e hegemónica nos últimos trinta anos. Isto significa que é preciso compreender de que forma a proposta teórica se desdobra num conjunto de propostas e implementações práticas, e como ambas transformam o sujeito através de novas técnicas disciplinadoras.

Não entrarei aqui nas definições contestadas de neoliberalismo. Parto de uma leitura de Harvey que vê o neoliberalismo como solução para uma crise de acumulação do capital na década de 1970, contestando a teoria económica de Keynes e propondo uma mudança de paradigma em que a desmaterialização monetária, flexibilidade financeira e reordenação das prioridades das políticas públicas em nome do capitalismo se tornam centrais. ${ }^{7}$ Neoliberalismo é assim um modelo que obriga a repensar o papel do Estado na economia, usando a categoria de governamentalidade para

6 Foucault diz: "o indivíduo não deve ser concebido como núcleo elementar, átomo primitivo, um material múltiplo e inerte no qual poder se exerce ou contra o qual ele se aplica, e ao fazê-lo, esmaga os indivíduos. De fato, [ele, o indivíduo] é um dos primeiros efeitos do poder que certos corpos, certos gestos, certos discursos, certos desejos, sejam identificados e constituídos enquanto indivíduos. O indivíduo, isto é, não é o vis-à-vis do poder; ele é, creio eu, um dos seus efeitos primários. (1998a, p. 98)' em McHOUL e GRACE, 1993, p. 73

7 Ver HARVEY, D., 2011. A brief history of neoliberalism. Nova York: Oxford University Press. 
dissolver as raízes dessa compartimentalização [entre estado, mercado e sociedade civil]'. As fronteiras entre público e privado, estado e nãoestado, político e não-político, são criadas e definidas dentro de um campo de governamentalidade através de séries de conflitos, continuidades e novas construções históricas que combinam ideologias com práticas e conhecimento técnico. Uma mudança na governamentalidade significa uma mudança nas formas como os mundos do estado e da vida são definidos e separados; as fronteiras entre estado, mercado e sociedade social são criadas pela governamentalidade, e não o contrário. A governamentalidade neoliberal é muito ativa e intervencionista, mesmo quando é 'mínima' (COTOI, 2011, p. 111, minha tradução).

Se a governamentalidade em Foucault significa 'a conduta das condutas', percebemos que a compreensão do que esta governamentalidade realmente implica é muito mais complexa do que pode inicialmente parecer. Governamentalidade diz respeito a novos 'regimes de verdade', i.e., à criação de novas condições ou modalidades que desenham as possibilidades de 'dizer a verdade' e 'compreender a verdade'. A verdade em Foucault nada tem a ver com o conceito epistemológico de 'verdade' pensada como correspondência ou 'crença verdadeira justificada'. É outro conceito de verdade que não se limita ao domínio do conhecimento, mas das práticas de si e dos outros, ou seja, que aponta para a camada invisível que permite que os visíveis se construam e se manifestem: os depoimentos, os discursos, as práticas, os sistemas de conhecimento inclusive. Esta perspectiva distinta de Foucault traduz-se na forma como ele coloca a questão: o autor nunca pergunta 'o que é?' mas sim 'como é?' ou 'como algo se torna aquilo que é?'. Ou seja, como as verdades se tornam verdades, através de que conflitos, alianças, violências, sujeições, se constituem enquanto tal?

A governamentalidade neoliberal coloca no seu centro de verdade o mercado, ou seja, parte da premissa liberal de que os indivíduos buscam apenas os seus interesses, são governados por eles, e que a nível da relação que estabelecem, ou devem estabelecer com o Estado, querem apenas ser 'deixados em paz', o que em grande parte está implícito na expressão laissez-faire, porém, transcende o liberalismo e transforma-o radicalmente: a questão não é mais a mera reivindicação de autonomia da economia face ao Estado, mas antes a priorização da economia sobre o Estado obrigando a que este permita e intervenha na redefinição das redes ou das várias relações de poder a nível político, social, etc., para que se compatibilizem com os ditames do mercado. Daqui se segue que o ideal neoliberal não é apenas o objeto de crítica de Marx, ou seja, a sociedade capitalista regulada apenas pelo valor-detroca. A sociedade capitalista baseada na valor-de-troca dá lugar a uma 
sociedade baseada na competição entre empresas múltiplas e distintas. Esta competição, por sua vez, vai exigir que o Estado garanta as suas condições de possibilidade, ou seja, vai exigir que o Estado intervenha, não no mercado, mas no tecido social, na estrutura básica da sociedade. O projeto neoliberal, sabendo-o ou não, é muito mais ambicioso, pois não reclama apenas o laissez-faire, mas a concorrência, a competição desenfreada. A magia do neoliberalismo é exatamente essa: ele governa sem dar a impressão de governar; ele governa não pela imposição ou restrição de liberdades, de condições de possibilidade de ação, mas pela redefinição do que 'liberdade' significa ou deve significar. Ele transforma o sistema de liberdades e de verdade: o sujeito tem liberdade de comprar, vender, ter propriedade, tem liberdade de expressão, de associação; mas a liberdade passa a ser algo a ser 'consumido', e se é 'consumido' tem que ser primeiramente 'produzido' e 'organizado'. Foucault diz:

A nova arte de governo aparece como gestão de liberdade, não no sentido do imperativo: 'sê livre', com a contradição imediata que este imperativo possa conter. A fórmula do liberalismo não é 'sê livre'. O liberalismo formula o seguinte: eu vou produzir o que tu precisas para ser livre. [...] Assim, se este liberalismo não é tanto o imperativo da liberdade mas antes a gestão e organização das condições sob as quais cada um pode ser livre, é claro que o que está no centro desta prática liberal é uma relação e uma problemática móvel sempre diferente entre a produção da liberdade e a produção na qual a produção de liberdade ameaça limitar e destruir. Liberalismo [...] implica no seu âmago uma relação produtiva/ destrutiva com a liberdade. [...] Liberalismo tem de produzir liberdade, mas este mesmo ato obriga ao estabelecimento de limitações, controles, formas de coerção e obrigações apoiadas em ameaças (FOUCAULT, 2008, p. 63-4). ${ }^{8}$

Se lembrarmos a frase celebre de Thatcher de que o objetivo do neoliberalismo é 'transformar a alma', percebemos que essa transformação começa e depende da redefinição da liberdade, pois esta tem sido a categoria crucial para pensar a própria subjetividade. Como diz

8 Tradução minha a partir da versão inglesa: 'The new art of government therefore appears as the management of freedom, not in the sense of the imperative: 'be free,' with the immediate contradiction that this imperative may contain. The formula of liberalism is not 'be free.' Liberalism formulates simply the following: I am going to produce what you need to be free. I am going to see to it that you are free to be free. And so, if this liberalism is not so much the imperative of freedom as the management and organization of the conditions in which one can be free, it is clear that at the heart of this liberal practice is an always different and mobile problematic relationship between the production of freedom and that which in the production of freedom risks limiting and destroying it. Liberalism as I understand it [...], entails at its heart a productive/ destructive relationship with freedom [...]. Liberalism must produce freedom, but this very act entails the establishment of limitations, controls, forms of coercion, and obligations relying on threats.' 
McGuigan, "embora o neoliberalismo seja antes de mais uma doutrina da economia política, é também [...] um princípio de civilização que molda o makeup sócio cultural das pessoas através da socialização, entendida no seu sentido mais amplo" (MCGUIGAN, 2014, p. 224). Foucault diz que nós vivemos na "era da governamentalidade" (FOUCAULT, 1991b, p. 103). Esta 'era' é paradoxal, na medida em que

se os problemas da governamentalidade e as técnicas de governo se tornaram a única questão política, o único espaço real para luta política e contestação, isto se deve ao fato de que a governamentalização do Estado é ao mesmo tempo o que permitiu que o Estado sobrevivesse, e é possível supor que se o Estado é o que é hoje, isso se deve à governamentalidade, que é simultaneamente interna e externa ao Estado, já que as táticas de governo que tornam possível a definição e redefinição contínua do que está no âmbito de competência do Estado e do que não está, o público versus o privado, e por assim em diante; assim, o Estado só pode ser compreendido na sua sobrevivência e nos seus limites na base de táticas gerais de governamentalidade (FOUCAULT, 1991b, p. 103).

É neste contexto generalizado e disperso que se constrói o sujeito neoliberal. Foucault identificou muito bem o momento de transformação de paradigma. $\mathrm{O}$ anúncio de um protoneoliberalismo ainda na década de 1930 num horizonte marcado pelo nazismo e que promovia o homo oeconomicus como o 'empresário de si', desvelava o que viria a acontecer: a transformação do discurso e com ela a transformação das práticas, transformação esta que nos representaria em última instância uma mudança radical de paradigma. Há muitos exemplos explícitos desta transformação, citarei apenas dois: o exemplo da educação e seus desdobramentos, e o exemplo do 'sujeito neoliberal' a quem são atribuídas características especificas.

Comecemos pelo exemplo da educação. A educação hoje não é vista apenas como espaço de aprendizagem, mas antes de 'investimento', um investimento 'pessoal' que exige sacrifícios e/ou vontade do sujeito que quer aprender, que se quer educar, que quer apostar na sua 'formação contínua'; este 'investimento' tem no seu oposto o reconhecimento e/ ou criação de necessários espaços de investimentos físicos, de capital, com a proliferação de universidades e institutos de ensino públicos, mas sobretudo privados. Mais do que nunca a aprendizagem está 'acessível' a quem queira entrar no processo, independentemente do 'objeto' de conhecimento ou área de aprendizagem. Esta guinada que acentua a necessidade de se educar para se manter competitivo, e num certo sentido, digno de existência socialmente reconhecida e reconhecível pelo(s) outros manifesta-se na introdução e naturalização de muitos outros termos ou conceitos como 'capital humano' ou 'capital social'. A 
expectativa criada ou imposta sobre os sujeitos no processo de formação de individualidade (ou pelo menos, individuação) requer que estes se constituam à luz, ao espelho, de determinadas categorias: o sujeito hoje deve ser 'flexível', 'com mobilidade', 'inovador' e em 'formação constante'. Não basta o investimento na educação temporalmente determinado; é preciso que este investimento seja contínuo, múltiplo, diverso, que o sujeito se ajuste a essa diversidade, por isso que ele seja flexível, que esteja atento às 'demandas do mercado', às 'expectativas' daqueles que são hierarquicamente superiores mas também do 'sistema' em si; é preciso que o sujeito aceite mover-se, movimentar-se fisicamente, é preciso que ele viaje e que esteja disposto a abdicar de uma série de objetivos que, se em gerações anteriores fariam sentido, por exemplo, a liberdade traduzida na instanciação da propriedade (de concretizar o sonho de uma casa própria, um trabalho fixo, permanente, para a vida) se torna não só utópico, mas indesejável. Assistimos a uma "aplicação de uma grelha económica a fenómenos sociais" (FOUCAULT, 2008, p. 239) que tem custos, custos reais, visíveis, mas sobretudo invisíveis, aqueles custos de que não nos apercebemos porque somos contemporâneos de nós mesmos, mas que mais tarde ou mais cedo se farão sentir no tipo de humanidade (ou desumanidade) que irão produzir. Foucault diz

Qual é a função desta generalização da forma de 'empresa'? Envolve estender o modelo econômico da procura e da demanda e do investimentocustos-lucro de forma a torná-lo o modelo de relações sociais e da própria existência, uma forma de relação do indivíduo consigo mesmo, com o tempo, com aqueles em seu redor, o grupo e a família (FOUCAULT, 2008, p. 242). ${ }^{9}$

O neoliberalismo vem aperfeiçoar a tendência de governamentalidade já em curso desde o século XVIII e afirma-se como 'governa-mentalidade' que alcança tudo, que não deixa nada de forma, que absorve e inclui tudo aquilo que lhe resiste, através da promoção de discursos que são progressivamente naturalizados. Chegamos a um processo de construção de subjetividade não mais regulado pelo ideal burguês revolucionário ou (anti)democrático do individualismo, mas antes pelo ideal da permanente (re)individuação. O sujeito é obrigado a ser 'racional', a perseguir os seus próprios interesses, a competir para vencer, a ser absolutamente responsável por todas as suas escolhas e consequências. Mas esta

\footnotetext{
9 Minha tradução. Na versão inglesa: 'What is the function of this generalization of the 'enterprise' form? [I]t involves extending the economic model of supply and demand and of investment-costs-profit so as to make it a model of social relations and of existence itself, a form of relationship of the individual to himself, time, those around him, the group, and the family.'
} 
individuação, embora apareça sob a forma de manifestação de liberdade individual, nada mais é do que obrigação gerada pela necessidade, muitas vezes da própria sobrevivência. Quando o sujeito não responde às expectativas que lhe são impostas, quando é ultrapassado na corrida e competição desmedida, ele deve ser 'punido', pois 'merece' punição por ter 'falhado'.

Este sentimento de 'falha', de não ter correspondido às expectativas de um sistema impessoal, sem cara e sem direção aparente (pelo menos uma direção que pudesse caminhar para uma autonomia maior) não é apenas uma intuição ou palpite. Este sentimento traduz-se nos números das estatísticas que por sua vez obriga a reavaliar as fronteiras e limites dos próprios discursos. Por exemplo, a depressão passou a configurar uma tendência dominante do século XXI. De acordo com a Organização Mundial de Saúde estima-se que 350 milhões de pessoas no mundo sofrem da doença, ou seja, 7\% da população mundial. Embora a depressão seja classificada de acordo com a sua intensidade (depressão maior ou menor), estima-se que no seu pior conduza ao suicídio e que $800 \mathrm{mil}$ pessoas se suicidam todos os anos, sendo a segunda causa de morte entre jovens de 15 a 29 anos. De entre aqueles que sofrem da doença, estima-se ainda que apenas $10 \%$ receba tratamento. ${ }^{10}$ Outro dado relevante é que $33 \%$ da população mundial sofre (ou já sofreu) de ansiedade - São Paulo é a líder do ranking, com $29 \%$ da população sofrendo algum tipo de perturbação mental. As perturbações mais comuns deste tipo são os transtornos de pânico e a ansiedade generalizada. A primeira traduz-se geralmente em ataques onde a pessoa começa a ter dificuldade de respirar, taquicardia, e chega a pensar e a acreditar realmente que vai morrer. A segunda traduz-se num sentimento generalizado de medo, de tensão, que trespassa toda a vida social, afetiva e laboral do sujeito. ${ }^{11}$ Especialistas dizem que a depressão é um dos maiores, senão o maior, problema de saúde pública em todas as regiões do mundo, e que esse problema está diretamente ligado aos fatores sociais.

Foucault, no texto "Politics and the study of discourse" diz:

Se há uma ligação entre a prática política e o discurso médico não é, parece-me, porque esta prática tenha primeiro transformado a consciência dos homens, a sua forma de perceber as coisas ou conceber o mundo, e depois formar o seu conhecimento e o seu conteúdo; nem é porque tenha sido inicialmente refletido, de forma mais ou menos clara ou sistemática, em conceitos, noções ou temas que subsequentemente

$10<$ http://www.who.int/mediacentre/factsheets/fs369/en/> . Acesso em: 8 set. 2016.

11 <http://www.progresso.com.br/caderno-a/ciencia-saude/oms-diz-que-33-da-populacaomundial-sofre-de-ansiedade >. Acesso em: 8 set. 2016. 
foram importados para a medicina. O elo é muito mais direto: a prática política não transforma o sentido ou a forma do discurso médico, mas as condições da sua emergência, a sua inserção e seu funcionamento; ela transformou o modo de existência do discurso médico (FOUCAULT, 1991a, p. 67).

Esta transformação ocorreu através de uma série coordenada de eventos ou mudanças: novos critérios para designar quem tem direito a fazer um discurso médico, nova delineação do 'objeto' médico, novas leis ou condições de assistência para aqueles que são doentes; novo modo de funcionamento do discurso médico como 'parte de um sistema de controle administrativo e político da população' (idem).

Hoje, estes fatores sociais, acredito, radicam na agora ideologia dominante do neoliberalismo, que transferiu um aparato econômicofinanceiro para todas as esferas do real. Esta mutação fez-se sentir particularmente na esfera do trabalho, aquela esfera que desde o início da teorização se desdobrava na dupla vertente de a) exercício de liberdade e autonomia individual e b) instanciação alienante quando esse exercício fosse usurpado do próprio (sujeito) em nome de um 'salário', 'sobrevivência' ou outro. Locke, Hegel e Marx mostraram o lado 'positivo', emancipador do trabalho; Marx explorou as vertentes de alienação contidas dialeticamente no conceito e prática do trabalho; porém, mesmo na denúncia do que o 'trabalho' (e o trabalhado assalariado) se tornara, este nunca deixara de ter o seu componente utópico, de esperança, de individualidade e autonomia. Hoje, como bem notou Safatle, "o núcleo ideológico mais avançado das sociedades capitalistas criou algo como um horizonte normativo do trabalho calcado na transformação de certas expectativas depositadas na crítica do trabalho em nova estrutura disciplinar" (SAFATLE, 2015, p. 37).

A forma como apresentam hoje o trabalho, mais flexível, menos territorial, mais inventivo ou, no extremo oposto, mais repetitivo, instrumental e degradante, anda lado a lado com a tendência de precarização e empobrecimento (para não falar aqui da feminização da pobreza global) e este compasso marca um dos grandes paradoxos do neoliberalismo: ao mesmo tempo que este promete o sucesso àqueles que aceitam o horizonte de desregulação e transformam a sua subjetividade de acordo com as exigências do momento, estas flexibilizações promovem a perda da estabilidade necessária à construção da própria subjetividade, e com isso, deparado com a perda de emprego, pressões laborais ou exigências de sucesso que ultrapassam medições ou quantificações temporais, os sujeitos cedem a patologias que passam a defini-los. Safatle diz: 
Uma sociedade é, acima de tudo, uma forma de produção de patologias, ou seja, de tradução do sofrimento na gramática ordenada de patologias. Uma gramática que será constantemente mobilizada a fim de fornecer ao sofrimento um encaminhamento terapêutico socialmente aceito. Desta forma, a questão fundamental para a reprodução social não é a determinação impositiva da normalidade, mas a organização diferencial das patologias possíveis. É assim que uma sociedade controla suas margens, as mesmas margens a partir das quais poderiam vir demandas de transformação (SAFATLE, 2015, p. 41-42).

Esta passagem é esclarecedora acerca da relação entre neoliberalismo, enquanto novo a priori histórico, condições de trabalho e produção de subjetividade. Se o a priori histórico é propício a, materialmente falando (via categoria e práticas laborais), uma série de 'desvios' comportamentais, sejam eles perturbações mentais ou outros, é preciso repensar esses desvios e integrá-los, alargando as 'margens'. Ao mesmo tempo, isso parece sugerir que todos os potenciais desvios podem ser facilmente incorporados, pela transformação dos discursos e da 'imagem' projetada acerca do que define o normal e o aceitável. Dito por outras palavras, se o sujeito neoliberal é este sujeito capturado por uma ideologia aparentemente hegemônica (e com isso o neoliberalismo deixa de ser ideologia e passa a ser apenas a 'grande narrativa', onde nada mais parece ser possível), como pensar e viabilizar momentos ou estratégias de transgressão? ${ }^{12}$

\section{Como transformarmo-nos?}

Chegámos assim ao último momento deste artigo, que pretende responder a esta questão: como transformarmos a nossa própria subjetividade? Em que direção o devemos fazer? Que tipo de subjetividade deve ser aspirada por nós? O meu objetivo aqui é identificar os elementos Foucaultianos que devem ser mantidos para transformar o sujeito atual num seu 'outro', imaginando que tipo de nova subjetividade podemos construir dentro das condições atuais que se nos apresentam. Para isso tomarei como textos de referência o último curso do Collège de France sobre o tema 'O governo de si e governo dos Outros'.

Foucault deixou-nos com uma herança difícil de gerir: ao mesmo tempo que o autor denunciou a impossibilidade de manter os grandes ideais universais, como Razão, Liberdade e Autonomia, esta denúncia sempre

12 Afinal, transgressão era para Foucault uma tática subversiva que 'trabalha nos limites que definiram maneiras de ser, de fazer, de pensar', ou seja, uma tática que atualiza a possibilidade da própria liberdade, sempre indefinida (FOUCAULT, 1997). 
teve um carácter ambíguo, na medida em que a meu ver Foucault se insere na tradição crítica inaugurada por Kant, e, como tal, se debate com a grande questão por este inaugurada no texto "O que é o Esclarecimento?", a saber, quem somos nós? Que sentido dar ao nosso presente?

Despojado de categorias com pretensões universalistas, o sujeito em Foucault desdobra-se nos sentidos de, por um lado, sujeitado, i.e., disciplinado, moldado, orientado, mas por outro, este sujeito disciplinado requer uma estratégia produtiva que se traduz na criação da identidade, com autonomia, mesmo que dentro de parâmetros previamente definidos. O indivíduo que, não esqueçamos, é uma invenção recente, constrói-se sempre na dualidade entre liberdade e dominação. Se a subjetividade em Foucault é uma categoria necessariamente ambígua, já que é o ponto de intersecção entre o eixo de 'sujeito' e o eixo de 'poder', e se ao mesmo tempo que tudo parece conduzir a uma formatação de 'quem' nós podemos ser, o que nos é permitido ser, a subjetividade é por excelência o espaço de luta política no contexto da 'governamentalidade' neoliberal. Se as técnicas neoliberais produzem subjetividades flexíveis, precárias, duais, patológicas, ou outras, então, como pensar os instrumentos de resistência e/ou transformação à neoliberalização?

Qualquer tarefa de 'resistência' ou 'transformação' assume que aquilo ao qual resiste ou aquilo que quer transformar não é o que deve ser ou é falso. Mas então, o que seria o verdadeiro? Será que podemos ainda falar em verdade, ainda mais no contexto ético de produção de subjetividades? Como fundamentar e como justificar a recusa pessoal e uma possível política de recusa? Retomando o que foi dito anteriormente a propósito da 'verdade' em Foucault, vale lembrar que o autor fala em termos de 'vontade de verdade' ou 'jogos de verdade', ou seja, as relações de poder manifestam-se na busca de institucionalização ou registo de verdades que compelem ao aperfeiçoamento desse mesmo 'modelo' implementado via uma multiplicidade de aparatos para a produção, circulação, acumulação e realização de verdade. Dito por outras palavras, a questão para Foucault não é saber o que é a verdade, mas antes, como certas coisas são tornadas verdadeiras. Tudo o que é tomado, aceite por verdadeiro é um produto de relações de poder. A verdade, nas palavras de Foucault, é um 'sistema de exclusão', ou seja, um sistema que se constrói a partir da eliminação da possibilidade de outros discursos e outras práticas. Do ponto de vista do sujeito, mesmo que os 'jogos de verdade' o afetem apenas de forma indireta, eles são de alguma forma interiorizados, permitindo que o sujeito se identifique ou se reconheça (a si mesmo). Neste contexto, a verdade 'traduz a experiência refletida pela qual o sujeito se constitui a si mesmo como sujeito ético, estabelecendo uma interpretação de si' (COSTA, 2011, p. 192). Mas se a verdade é 
um espelho das construções sociais, culturais e históricas, que tipo de verdade pode o sujeito construir, ou atribuir a si? Por outras palavras, como é que a verdade é subjetivada e tornada pessoal? (idem) E por fim, como essa construção requer uma desconstrução anterior de si?

O conceito de desconstrução é importante porque aponta para o sentido inaugurado por Derrida de inversão de hierarquias, de questionamento do dado a partir da vivência poiética, sendo sempre um acontecimento por vir; dito de outra forma, a desconstrução que não é método nem crítica (no sentido em que não se reduz a estes), que permanece, de alguma forma, indefinível, consiste no processo de deslocamento e de desestabilização de sentidos, na erupção de um 'acontecimento', na estratégia de abertura de possibilidades. ${ }^{13}$ Claro, a desconstrução em Derrida aplica-se ou situa-se no texto, é referida ao texto. Como diz o autor, 'não existe nada fora do texto', mas podemos perceber uma semelhança entre Derrida e Foucault na medida em que ambos criam espaço para o Outro ou para os 'outros', do discurso e das práticas. Perguntar como o sujeito se pode (re)construir significa perguntar acerca das condições de possibilidade do 'outro' de si. Isso passa pela reapropriação de práticas e ressignificação das mesmas. O conceito de verdade desempenha um papel fundamental para tentar imaginar as possibilidades de transformação do sujeito neoliberal.

Entendo a 'verdade' aqui não no sentido de correspondência entre $\mathrm{x}$ e y, mas como produção consciente e engajamento com um projeto de vida seu. À luz disto podemos compreender a resistência de Foucault em definir alternativas concretas ou sugestões de ação. Dada a capacidade incessante de absorção do neoliberalismo e do capitalismo ultra-avançado em que vivemos, toda e qualquer estratégia explicita de resistência seria facilmente incorporada como componente estrutural do regime de dominação pós-disciplinador. ${ }^{14}$ Tudo hoje nos leva ao excesso de individuação, da atomização, da identificação entre sujeito-empresa (com todas as categorias que o mercado implica e são subjetivadas). Este movimento traduz-se no isolamento, na perda de capacidades sociais, relacionais, na despolitização, já que o sujeito neoliberal parece ter poucas condições para criar pontes físicas e simbólicas com os outros

${ }^{13}$ Derrida diz “(...) il fallait faire droit, de façon encore plus radicale, plus analytique, à la requête traditionnelle, à la loi même de ce qui venait à être déconstruit: d'où des concepts impossibles, des quasi-concepts, des concepts que j'appelais quasi transcendantaux, comme l'archi-trace ou l'archi-écriture, l'archi-originaire plus 'ancien' que l'origine - et surtout une affirmation donatrice qui reste l'ultime inconnue pour l'analyse qu'elle met pourtant en mouvement." (DERRIDA, 1996, p. 44).

14 "A typical strategy of neo-liberalism is to take something originally devised as a strategy of resistance and to incorporate it as a structural component of the regime of domination precisely the reason why Foucault was reluctant to offer alternatives rather than critique." (HOFMEYR, 2011, p. 28). 
sujeitos que lhe permitiriam participar pela luta por políticas públicas e assim, construir o mundo onde ele mesmo vive. ${ }^{15}$ Mas então, como pode a verdade romper com esse movimento dominante de reprodução de nós mesmos enquanto sujeitos neoliberais?

No curso dado por Foucault no Collège de France em 1982 e 1983, intitulado "O governo de si e dos Outros" Foucault regressa uma vez mais ao texto emblemático de Kant (o que é o esclarecimento?), porém agora como ponto de partida para dialogar com os gregos. O retorno aos gregos no último período da sua escrita pode ser interpretado como resistência ao peso e história da modernidade. Com efeito, podemos imaginar que a experiência dos gregos (tal como interpretada pelo autor) nos pode dar alguns indícios de como resistir aos processos de subjetivação impostos pela grelha moderna e neoliberal. A introdução do conceito de parresía indica uma estratégia possível para a dessubjetivação e reconstituição de si como sujeito ético. Essa estratégia parte do reconhecimento de uma relação estreita entre a forma como o sujeito se constitui e como se relaciona com o mundo. ${ }^{16}$ Vejamos.

Foucault defendeu em obras anteriores que o sujeito moderno se define pelo acesso que tem à verdade, ou seja, no contexto neoliberal o sujeito reconhece uma determinada lógica, conjunto de regras, imperativos e costumes como verdadeiras às quais ele deve se submeter ou pelas quais ele deve orientar a sua conduta. O processo de subjetivação é contínuo, ele requer um trabalho constante sobre si próprio. O exemplo da educação mostra exatamente isso: não basta fazer um curso de graduação ou pósgraduação; é preciso entrar num processo de formação continua que pode e deve ser interpretada como processo de subjetivação (o tornar-se sujeito neoliberal) dentro do que é esperado pelo a priori histórico. O ser e tornar-se um bom sujeito, um sujeito dócil, controlável, expectável, revela

15 Como diz Hofmeyr, "tendo constantemente de competir com colegas e consigo mesmo corrói a solidariedade dos sujeitos, entendida como parceria emergindo de responsabilidades, interesses e propósitos comuns. É a solidariedade que dota os sujeitos do poder da comunidade, que inclui a credibilidade e o poder para mudar as coisas. A individualização implica necessariamente a despolitização: o sujeito neoliberal já não é um cidadão entre outros, empoderado para contestar e transformar as políticas que governam a sua existência, mas antes uma entidade insular, lutando apenas para sobreviver num mundo que não é feito por ele" (HOFMEYR, 2011, p. 26, minha tradução). No original: "having constantly to compete with colleagues and with oneself corrodes the solidarity of subjects, understood as a fellowship arising from common responsibilities, interests and purpose. It is solidarity that endows subjects with the power of community, which includes the credibility and the power to change things. Individualization necessarily entails depoliticization: the neo-liberal subject is no longer a citizen amongst others empowered to challenge and change the policies governing its existence, but an insular entity merely struggling to survive in a world that is not of its own making."

${ }^{16}$ Vários autores têm recuperado recentemente a leitura do último Foucault e as implicações do conceito e prática de parrhesia a nível ético e político. Ver Dianna Taylor (2013), Amy Allen (2016), entre outros. 
a relação necessária entre subjetividade e obediência (TAYLOR, 2013, p.90). ${ }^{17}$ Se o sujeito normal e normalizado se torna tão previsível, talvez a solução seja rejeitar essas tecnologias que exigem tantos sacrifícios e inventar novas formas de relação consigo mesmo. ${ }^{18}$ Uma possibilidade prende-se com a parresía: uma prática de dizer a verdade que tem um efeito duplo: um efeito sobre si mesmo e um efeito sobre e para o outro. Efeito sobre si mesmo, na medida em que o dizer a verdade ao outro significa por um lado, ter coragem, por outro, colocar-se em risco, inclusive risco de vida, pois a reação do outro que escuta a verdade é imprevisível. Efeito para o outro, na medida em que esse outro pode reagir de diferentes maneiras quando confrontado com a verdade. Mas há uma condição: aquele que diz a verdade tem uma relação particular consigo mesmo:

A parresía é uma maneira de se vincular a si mesmo no enunciado da verdade, de vincular livremente a si mesmo e na forma de um ato corajoso. A parresía é a livre coragem pela qual você se vincula a si mesmo no ato de dizer a verdade. Ou ainda, a parresía é a ética do dizer-a-verdade, em seu ato arriscado e livre (FOUCAULT, 2013, p. 64).

Dito por outras palavras, 'Sempre há parresía quando o dizer-averdade se diz em condições tais que o fato de dizer a verdade, e o fato de tê-la dito, vai ou pode ou deve acarretar consequências custosas para os que disseram a verdade' (FOUCAULT, 2013, p. 55).

A fala franca, o dizer-a-verdade, rompe com o paradigma estabelecido da obediência calculada e cega; ela põe em atividade a liberdade enquanto coragem e enquanto risco, incluindo risco de vida. Neste sentido, o dizer-a-verdade representa a possibilidade de se construir e de se afirmar enquanto aquele que diz a verdade, indivíduo livre que aceita o risco que essa liberdade implica, e que não se reduz nem pode ser limitado ao seu lugar pré-definido pela rede de instituições. A verdade obriga a um pacto consigo mesmo. Como diz Taylor

uma autorrelação parresiástica representa o que em termos modernos/ contemporâneos pode ser caracterizado como uma alternativa antinormalizadora à autorrelação confessional que a subjetividade herda e reproduz. Não só a autorrelação parresiástica não promove a autorrenúncia e obediência, como a forma particular pela qual o tipo desta autorrelação opõe a autorrenúncia e obediência cria a oportunidade de constituir, compreender e relacionarmo-nos a nós mesmos de forma diferente (TAYLOR, 2013, p. 96, minha tradução).

${ }^{17}$ Para análise mais detalhada desta relação ver Foucault, M., 2014, A Hermenêutica do Sujeito, São Paulo: Martins Fontes.

${ }^{18}$ Ver Taylor, 2013, p. 92 onde a autora cita uma palestra de Foucault dada na Universidade de Berkeley a 20 e 21 de outubro de 1981 sobre "Cristianismo e Confissão". 
A parresía cria a oportunidade do indivíduo que fala se de-subjetivar e se reconstituir de outro modo; ou seja, a fala franca é um ato crítico na medida em que denuncia o que é e o que está errado (por exemplo, pode denunciar a injustiça) e ao fazê-lo afirma a prática da liberdade como poder de reconfigurar as relações de poder instituídas e normalizadas. É neste sentido que, pelo conceito de parresía, Foucault consegue articular a dimensão individual, do sujeito que fala, que diz a verdade, com a dimensão coletiva, da comunidade política onde ele se insere. A parresía, nesse sentido, é indispensável para se pensar a democracia; ela é o outro lado da democracia, sua fundação e seu princípio regulador. Na parresía podemos talvez encontrar a possibilidade e esperança de subversão da sociedade de normalização que promove a aceitação acrítica de modos de subjetivação, porque a parresía é uma prática humana, uma prática de liberdade que se expõe e se constrói no risco, no imprevisível. Dito por outras palavras, a parresía rompe com o construído e desconstrói o dado, expõe e cria um acontecimento (événement), ela expõe o seu outro, ela denuncia a injustiça. Nisto, podemos perceber a relação intima entre parresía, crítica e democracia.

A parresía tem uma estrutura agonística (FOUCAULT, 2013, p. 146), ela revela e trabalha sobre o conflito; ela caracteriza uma dinâmica de tensão, de movimento constante e de luta. Mas a parresía supõe um conjunto de atributos ou virtudes morais que, quando em falta, colocam o projeto democrático em risco. Essas virtudes são a integridade moral, a segurança e a resistência à corrupção (FOUCAULT, 2013, p. 165). Não se trata apenas de saber onde está a verdade, ou o que seria o interesse geral da comunidade política; no contexto atual significaria dizer, não se trata apenas de saber o que está errado com as técnicas e discursos neoliberais e o que estaria certo (um compromisso radical com os valores fundadores da democracia, a saber, a isegoria e a isonomia). É preciso ainda que aquele que diz a verdade aos outros, à comunidade política, tenha logos suficiente, e capacidade de persuasão para convencer os que o escutam da verdade do que diz, nas palavras de Foucault, ter os talentos de 'discernir o interesse público e expô-lo adequadamente'. (idem) Pressente-se de imediato o paradoxo a que a parresía conduz, pelo seu outro lado de democracia. Ao mesmo tempo que requer isegoria o seu sucesso depende do reconhecimento de uma superioridade, daquele que diz-a-verdade.

Não entraremos aqui nos detalhes e implicações da leitura de parresía e democracia em Foucault. Queria apenas apontar para uma estratégia possível de transformação do sujeito neoliberal que se prende com a transformação da relação consigo mesmo, via verdade, e consequentemente, na relação com os outros. Parece-me que os escritos 
de Foucault sobre parresía cumprem a função de, por um lado, revelar os paradoxos, as dificuldades, da nossa condição presente, mesmo que essa revelação seja feita de forma indireta, por um discurso e regresso aos gregos; por outro lado, mostrar que é no confronto com os paradoxos e contradições que se encontra a possibilidade de redefinição de si a partir de uma reapropriação da prática de liberdade.

A consciência de que a anarquia dos desejos, a qual parecemos submetidos e submissos na sociedade neoliberal de consumo, expulsa o discurso verdadeiro (FOUCAULT, 2013, p. 184), é um primeiro passo, crítico, para a inversão das nossas práticas. Neste sentido, a crítica permanece o fio condutor na tarefa de reconstrução e reinvenção de nós mesmos. Como Foucault diz

Crítica é o movimento pelo qual o sujeito se dá a si mesmo o direito de questionar a verdade no que diz respeito aos seus efeitos de poder e questionar o poder acerca dos seus discursos de verdade. Crítica será a arte da inservilitude voluntária ou indocilidade refletiva' (FOUCAULT, 1997, p. 386).

Crítica é uma forma de viver, é uma prática concreta de liberdade; é um exercício continuo de autoconstrução, do governo de si mesmo, mas é também o ato pelo qual, ao questionar os regimes de verdade que nos moldam e nos quais nos espelhamos, questionamos o nosso próprio estatuto ontológico e com isso abrimos o espaço à reinvenção de nós mesmos.

A crítica, por isso, é a atividade que requer o vai-e-vem constante entre o que é e o que deve ser; o que 'deve ser' não tem necessariamente de ser definido positivamente, já que qualquer tentativa de definição seria incorporada por aquilo que ela visa superar ou transformar. $O$ 'dever-ser' é quase definido, e apenas provisoriamente, como recusa do que é e como vontade de ser-outro. A crítica, enquanto instrumento, metodologia e finalidade, é sempre criativa. Ela não visa apenas à denúncia, mas à construção do diferente, do imprevisível, do inesperado. Neste sentido, a crítica, criativa porque negadora, é a condição e a manifestação primeira da política. A política - e a política que é sempre democrática, isto é, fundada pela parresía - é o oposto do que o neoliberalismo prega, espera e exige: a individuação. A resistência ao que é começa pela resistência a permanecer só e isolado; estar com o outro é, no paradigma em que nos encontramos, um ato de resistência, porque se propõe, mesmo que inconscientemente, a restabelecer os elos quebrados pelas narrativas e estruturas visíveis e invisíveis que são dominantes. A resistência é esse ato crítico de recusa (do que é) e de afirmação do que pode ser pela e na relação com o outro. 


\section{Referências}

BALL, S. J. "Subjectivity as a site of struggle: refusing neoliberalism?" British Journal of Sociology of Education, London/New York: Routledge, 2015. 10.1080/ 01425692.2015.1044072

BUTLER, J. Giving an Account of Oneself. New York: Fordham University Press, 2005. COSTA, M. N. Redefining Individuality. Vila Nova Famalicão: Húmus Ed., 2011. COTOI, C. "Neoliberalism: a Foucauldian Perspective". International Review of Social Research, 1, 2 (June 2011), p. 109-124.

DERRIDA, J. Résistances de la psychanalyse. Paris: Éditions Galilée, 1996. FOUCAULT, M. “The Subject and Power". Critical Inquiry, 8, 4 (1982), p. 777-795.

. "O sujeito e o poder". In: RABINOW, P.; DREYFUS, H. Foucault: uma trajetória filosófica. Rio de Janeiro: Forense Universitária, 1995. p. 231-249.

. "Why Study Power: The Question of the Subject". In: DREYFUS, H.; RABINOW, P. (Ed.). Michel Foucault: Beyond Structuralism and Hermeneutics. Chicago: University of Chicago Press, 1983.

. "What is Enlightenment?" In: RABINOW, P. (Ed.). The Foucault Reader. New York: Pantheon Books, 1984.

"Politics and The Study of Discourse". In: GORDON, C. et al. (Ed.). The Foucault Effect - Studies in Governmentality. Chicago: University of Chicago Press, 1991a. p. 53-72.

. "Governmentality". In: GORDON, C. et al. (Eds.). The Foucault Effect-Studies in Governmentality, Chicago: University of Chicago Press, 1991b. p. 87-104.

. "What is Critique?" In: LOTRINGER, S.; HOCHROTH, L. (Eds.). The Politics

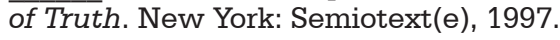

. Birth of Biopolitics: Lectures at the College de France 1978-79. New York: Palgrave Macmillan, 2008.

. O governo de si e dos outros. São Paulo: Martins Fontes, 2013.

HARVEY, D. A brief history of neoliberalism. Nova York: Oxford University Press, 2011. HOFMEYR, B. 'The Culture and Subjectivity of neo-liberal governmentality'. Phronimon, 12, 2 (2011), p. 20-42.

McHOUL, A.; GRACE, W. A Foucault Primer - Discourse, power and the subject, London/New York: Routledge, 1993.

MCGUIGAN, J. 'The Neoliberal Self'. Culture Unbound - Journal of Current Cultural Research, 6 (2014), p. 223-240.

SAFATLE, V.P. 2015. 'O trabalho do impróprio e os afetos da flexibilização' em Veritas, Porto Alegre, 60 (jan-abr 2015), p. 12-49.

TAYLOR, D., 2013. 'Resisting the Subject: A Feminist-Foucauldian Approach to Countering Sexual Violence'. Foucault Studies, 16 (set. 2013), p. 88-103.

\section{Endereço postal:}

Programa de Pós-Graduação em Filosofia - UFSM

Av. Roraima, 1000, prédio 74-A, sala 2308

Santa Maria, RS

Data de recebimento: 08-09-2016

Data de aceite: 05-07-2017 